\title{
El papel de la justicia social como interviniente en la paz judía: la
} tsedaqá

\section{The Role of Social Justice as an Intervener in Jewish Peace: The Tsedaqá}

\author{
Tania Maria García Arévalo* \\ Universidad de Granada, España \\ http://orcid.org/0000-0002-4100-445X
}

Artículo de investigación

Fecha de recepción: 29 de febrero de 2020

Fecha de aceptación: 2 de abril de 2020

\section{Para citar este artículo}

García Arévalo, T. M. (2020). El papel de la justicia social como interviniente en la paz judía: la tsedaqá. Campos en Ciencias Sociales, 8(2), 111-131. Dor: https://doi. org/10.15332/25006681/6014

\section{RESUMEN}

Uno de los preceptos de la religión judía, contenido tanto en la ley escrita como en la ley oral, es el de la tsedaqá. Este concepto, que podría traducirse como "rectitud", se aproximaría al ámbito de la justicia social, en el sentido de que su objetivo sería paliar o revertir aquellas situaciones de desigualdad contenidas dentro de la sociedad a través de los actos de caridad de sus integrantes. Su práctica continuada por parte de los piadosos llevaría, por lo tanto, al tikkun ha-olam; esto es, a conseguir una mejora de la sociedad, cuya consecuencia final

Docente e investigadora del Departamento de Estudios Semíticos, Área de Estudios Hebreos y Arameos, y miembro del Instituto de la Paz y los Conflictos, Universidad de Granada, España. Sus campos de estudios se mueven en la lingüística, la literatura judeoárabe moderna, las comunidades judías del Magreb y su inserción en la Europa moderna y contemporánea. Correo electrónico: taniagarcia@ugr.es 
sería la reparación del mundo, ya que el objetivo de paz estaría completo o más próximo a su conclusión. En estas páginas nos centraremos en el desarrollo de este término y en el modo en que ha sido transmitido oralmente a través de la literatura en época contemporánea como valor dentro de una cultura educativa.

Palabras clave: justicia social, paz, judaísmo, literatura contemporánea, actos de caridad, cultura educativa.

\begin{abstract}
One of the precepts of the Jewish religion, contained in both written and oral law, is that of Tzedakah. This concept, which could be translated as "righteousness", can be thought of as germane to the field of social justice, insofar as its objective is to alleviate or reverse those situations of inequality contained in the center society through the acts of charity of its members. Its continued practice by the pious would therefore lead to Tikkun ha-Olam, that is, to an improvement in society whose ultimate consequence would be the reparation of the world, since the goal of peace would be complete or closer to its conclusion. In these pages we will focus on the development of this term and how it has been transmitted orally through contemporary literature as a value within an educational culture.
\end{abstract}

Keywords: social justice, peace, judaism, contemporary literature, acts of charity, educational culture.

\title{
INTRODUCCIÓN
}

Históricamente, el judaísmo es la primera de las tres grandes religiones monoteístas, junto con el cristianismo y el islam. Todas ellas se caracterizan por: haber surgido en un contexto semita geográfico concreto, el de la Palestina y Arabia; originarse en un periodo temporal entre el siglo viI a. e. c. y el viI d. e. c.; ser monoteístas — creyendo en la existencia de un único Dios_- no monólatras — reconociendo la existencia de una multiplicidad de ellos, se escoge la consideración de uno—; y por la relación que, en su conjunto, mantienen con el patriarca Abraham. 
Efectivamente, este examen y conciencia de compartir unas particularidades concretas comunes hace que sean agrupadas, según el prisma del islam y amparado por ciertas prácticas del profeta Muhammad y del califa Umar ibn al-Jattab en su entrada en Jerusalén (638 d. e. c.), bajo la denominación de gentes del Libro o dimmies. Este término fue utilizado por los musulmanes para categorizar a judíos y cristianos en tierras del islam, confiriéndoles un estatuto especial que, grosso modo, se limita a determinadas libertades y derechos jurídicos y religiosos sujetos al pago de tributos.

En lo concerniente al judaísmo, no solamente podemos referirnos a este como una religión, sino como un conjunto de prácticas y tradiciones relacionados con una forma de vida sujeta a ciertos textos. De esta forma, los judíos poseen la ley escrita, conocida bajo el acrónimo de $\operatorname{TaNaK}$, que contiene la Torá (Génesis, Éxodo, Números, Levítico y Deuteronomio) —que supondría el corpus legal—, Nebi’im (profetas) y Ketubim (“escritos", todos aquellos que no pertenecen ni al corpus legal ni profético) y que conformaría la Biblia Hebrea. Bajo la perspectiva cristiana, esto responde a la denominación de Antiguo Testamento, cuya redacción se prolongó a lo largo de los siglos y en la que se vieron envueltas muchas tradiciones. Por otra parte y recogida en el Talmud (de Babilonia y de Jerusalén, compuesto por la Mishná — recopilación de debates en hebreo_- y la Guemará — añadido final en arameo_-), está la ley oral, cuyo propósito es el de agrupar las discusiones de sabios rabinos en torno al corpus anterior; esto por las dudas que se pudieran extraer de él, sin contradecir, en ningún caso, a la ley escrita.

Tanto en la ley escrita como en la oral, los preceptos asociados con la práctica del judaísmo no solamente se relacionan con la experiencia de un usuario como parte integrante e integradora de una religión, sino que, a su vez, poseen un componente eminentemente ético, en el que las cuestiones morales destacan por su importancia. En este sentido, considero que Kellner (1995) señala oportunamente que no se puede olvidar el hecho de que el sustrato del que parten los principios éticos en el judaísmo es eminentemente religioso, sin que puedan llegar a distinguirse la ética y la ley judía (Idareta-Goldaracena, 2016, p. 129). 
No obstante, también debemos puntualizar que los mandatos o mitzvot del judaísmo parten de diferente naturaleza y no todos ellos plantean la superación de un problema ético. En la obra Mishné Torá ("Segunda Ley") — que es, por otro lado, la más autorizada de la ley judía—, el sabio cordobés Maimónides agrupa las leyes bíblicas y mishnaicas así: religiosas, que abarcan los principios y dogmas generales del judaísmo, tales como el culto, la celebración de las fiestas, las normas de pureza; civiles, relacionadas con el derecho público y privado del individuo o la colectividad; domésticas y sexuales, como el matrimonio, divorcio, relaciones prohibidas; dietéticas, las leyes del Kashrut, alimentos permitidos y no permitidos especificados en la categoría de animales puros o impuros, ciertas combinaciones de aquellos y la manera de prepararlos; cultuales, relativas a los deberes para con Dios; y, por último, las éticas, basadas en la caridad, amor al prójimo, préstamos, huérfanos y viudas, o el diezmo (Alba, 2004, p. 12). También podemos incluir al mandato de la tsedaqá - traducido como justicia y equidad, pero, del mismo modo, con los conceptos de limosna y caridad - del que nos ocuparemos a continuación y que se retribuye de manera positiva o negativa según su cumplimiento.

\section{LA TSEDAQÁ COMO MEDIO PARA EL TIKKUN HA-OLAM: INSTRUMENTOS DE REPARACIÓN Y MEJORA DE LA SOCIEDAD}

El concepto tsedaqá en la lexicografía se traduce como: equidad, honestidad, honradez, rectitud, integridad, inocencia, justicia, derecho/justificación, salvación, triunfo, victoria/crédito, mérito, virtud, piedad. Esto, ciertamente, es lo que se observa en los textos bíblicos, como en Isaías 32, 17: "Y la obra de la justicia será la paz, y el fruto de la justicia, la tranquilidad y la seguridad para siempre" (Isaías 32, 17, Cantera-Iglesias, 2000); "Guardad el derecho y practicad la justicia" (Isaías, 56, 1); “ $\mathrm{iAy}$ de aquellos que decretan decretos inicuos y de quienes hacen escribir escritos dañinos, marginando el juicio de los débiles y despojando del derecho a los pobres de mi pueblo de modo que las viudas son su presa y a los huérfanos saquean!" (Isaías 10, 1-2). Por otra parte, en Deuteronomio se encuentra con el sentido de diezmo con el objetivo de socorrer a los pobres: 
Al fin de [cada] tres ańos separarás todo el diezmo de tu cosecha en aquel año y lo depositarás en tus ciudades, y vendrá el levita — pues no tiene contigo porción ni herencia-, y el extranjero, el huérfano y la viuda que haya en tus ciudades, y comerán y se saciarán, a fin de que Yahveh, tu Dios, te bendiga en toda obra que tu mano acometa. $(14,28-29)$

Cuando hayas acabado de diezmar todo el diezmo de tu cosecha, al tercer año, el año del diezmo, y lo hayas dado al levita, al extranjero, al huérfano y la viuda, para que coman en tus ciudades y se sacien, dirás ante Yahveh, tu Dios: He extirpado de cada lo consagrado y, además, lo he dado al levita, al extranjero, al huérfano y la viuda, conforme a todo el precepto que me prescribiste; no he traspasado ninguno de tus mandatos ni los he olvidado. No he comido de ello durante mi duelo, ni me he llevado de ello nada que fuese impuro, ni he dado de ello para un muerto; he escuchado la voz de Yahveh, mi Dios; he obrado conforme a cuanto me has mandado. (26, 12-14)

Estos versículos del Deuteronomio explican que los pobres debían recibir el diezmo del tercer año, al igual que los levitas, lo que era una forma de hacer justicia y solucionar, en lo que fuera posible, la situación de ambos grupos, pues ninguno tenía derecho a poseer tierras, como sí lo tenían las tribus de Israel (Martínez, 2009, p. 76). Según Joachim Jeremías (1977, p. 152), se podría argumentar incluso que la legislación del Antiguo Testamento, en materia de ayuda a los necesitados, sería generosa en virtud de los textos. Como apunta Manuel Fraijó (1985, p. 46), a esto convendría añadir que era usual que los pobres se congregaran alrededor del Templo para conseguir limosna y que, darla, era considerado un hecho especialmente meritorio.

Sin embargo, el sentido del vocablo en los textos rabínicos se extiende a los de caridad, dádiva, limosna, beneficencia. Así se recoge en el Talmud de Babilonia:

Pero ¿por qué fue destruido el segundo Templo, ya que en su tiempo estaban ocupando ellos mismos con la Torá, [la observancia de] preceptos y la práctica de la caridad? Porque allí prevaleció el odio sin causa. Eso te enseña que el odio sin sentido es considerado como de igual gravedad con los tres pecados 
capitales de idolatría, inmoralidad y derramamiento de sangre juntos. (Tratado Yoma 9b)

En el Tratado Sanhedrín:

R. Joshua b. Korha dice: La solución de compromiso es un acto meritorio, porque es escrito, "Ejecuta el juicio de verdad y paz en tus puertas; y que ninguno de ustedes diseña el mal en tus corazones contra su prójimo" (Zac. 8, 16-17). Seguramente donde hay justicia estricta no hay paz, y donde hay paz, ¡no hay justicia estricta! Pero, ¡cuál es ese tipo de justicia con la que permanece la paz? Debemos decir: arbitraje. Así fue en el caso de David, mientras leemos: "Y David ejecutó la justicia y justicia [caridad] hacia todo su pueblo" (II Sam. $8,15)$. Seguramente donde hay justicia estricta no hay caridad, y donde hay caridad, ¡no hay justicia! Pero, ¿cuál es el tipo de justicia con la que permanece la caridad? Debemos decir: arbitraje. (Sanhedrín 6b)

En el Talmud de Babilonia, Baba Batra 9a: "la caridad [tsedakah] es tan importante como todos los otros mandamientos juntos"; también en Baba Batra 10a, Sanhedrín $111 \mathrm{~b}$, dar limosna se consideraba como un acto de idolatría. Incluso Maimónides, en su Mishne Torá, lo plasmaba de la siguiente manera:

Al principio, es una mitzvá preguntar a los litigantes: ‘¿Deseas un juicio o ¿un compromiso?' Si desean un compromiso, se negocia un compromiso. Ninguna El tribunal que negocia continuamente un compromiso es digno de elogio. Sobre [esto acercarse, Zac. 8, 16] dice: "Juzga un juicio de paz en tus puertas”. ¿Qué juicio implica paz? Un compromiso. Del mismo modo, con respecto al rey David declaró: "Y David llevó a cabo justicia y caridad para todo su pueblo". ¿Cuándo hace la justicia implica caridad? Cuando se hace un compromiso. ¿Cuándo se aplica lo anterior? Antes de emitir un juicio. A pesar de que [el juez] ya ha escuchado sus argumentos y sabe en qué dirección se dirige el juicio, es una mitzvá para negociar un compromiso. Una vez que se dicta la sentencia y declara: "Tal y tal, su reclamo está justificado y tal y tal, usted es responsable", no puede negociar un compromiso. En cambio, deja que 
el juicio atraviese la montańa. Aunque los litigantes acordaron un compromiso en la corte, [los jueces] tienen la autoridad para exigir un juicio hasta que los litigantes confirmen su compromiso [con el compromiso] con un kinyan [adquisición]. Un compromiso tiene mayor poder legal que un juicio. Si dos personas emiten un juicio, su juicio no es vinculante y los litigantes no necesitan aceptar eso. Sin embargo, si [tales individuos] negociaron un compromiso y los litigantes afirmaron [su acuerdo] con un kinyan [adquisición], no pueden retractarse. (Mishné Torah, Leyes del Sanhedrín, leyes 4-6 del capítulo 22)

Gurfinkiel (2017) arguye que, además, Maimónides comenta que el precepto de la caridad debe cumplirse con mucho mayor celo que cualquiera de los otros numerosos mandatos, pues es la señal distintiva de ser un hombre justo. De los ocho grados de caridad que expone en su Mishné Torá, el más alto de todos es el del que acude en ayuda del judío necesitado, dándole un obsequio o un préstamo, tomándolo como socio, o proveyéndole una tarea que pueda hacer hasta que se recupere y no necesite acudir más a la caridad. De este modo, la caridad preventiva es preferible a la paliativa, en tanto permite al auxiliado llegar a ser autosuficiente (2017, p. 225).

Si bien es cierto que en la literatura rabínica son muchos los textos, como los anteriores, en los que se hace referencia a los más necesitados, la caridad y la limosna, el tratado mishnaico que por excelencia se ocupa de estas cuestiones es el de Peah (T. lit. esquina del campo) y su división Zeraim (T. lit. semillas). Peah trata sobre el derecho de los pobres a tener acceso a ciertas porciones de los frutos o producto agrícola para su uso exclusivo. De acuerdo con la ley escrita, Dios exigía que en Israel los terratenientes o dueños de campos cultivables dedicaran una parte de los frutos del campo a los necesitados, mientras que otras dádivas llegaban a ser propiedad de los pobres por medio de accidentes ocurridos en el campo.

Los sabios que diseñaron Peah creían que todos los dueños de tierras en Israel eran responsables del bienestar material de los pobres en su vecindad (Martínez, 2009, p. 78). Tal y como Aquiles E. Martínez argumenta, para los rabinos lo urgente no solo era ayudar, sino también hacerlo de la mejor manera posible, aunque esto dependía de corrientes de pensamiento e individualidades, con visiones del mundo 
y sistemas éticos propios que respondían a los desafíos sociales (2009, p. 77). De ahí la importancia de la codificación de Peah, que surge como una acción necesaria para paliar el bienestar material de los más necesitados. De esta manera, al final del siglo II d. e. c., ya se había elaborado un cuerpo sistemático de leyes y regulaciones para facilitar el cumplimiento de los mandatos divinos con respecto a esta cuestión (Martínez, 2009, p. 78; Brooks, 1990, p. 3 y 1983).

Pese a que no es el objetivo de estas páginas desarrollar el extenso contenido y argumentaciones que exhibe Peah, sí hemos de tener claro que la naturaleza de las 69 regulaciones en ella se basa en la discusión de todas las casuísticas de la caridad, sosteniendo esta como uno de los pilares fundamentales que deben ser cumplidos:

Estas son las cosas que no tienen medida fija: las esquinas del campo, los primeros frutos, las ofrendas traídas a los festivales al presentarse ante el Eterno, la caridad y el estudio de la Torá. Estas son las cosas de cuyos frutos el hombre disfruta en este mundo, y el depósito de lo que permanece para él en el mundo venidero: honrar a padre y madre, la caridad y hacer la paz entre un hombre y su prójimo. No obstante, el estudio de la Torá es igual a todas ellas. (Peah 1, 1, su explicación puede consultarse en Brooks, 1983, pp. 42-48)

De este fragmento se extrae la igualdad de tres pilares: la honra a los ancestros, el culto divino y la Torá, y las obras de misericordia. Por otra parte, además, sostiene que "quien no permita que los pobres espiguen o permita que uno lo haga y no el otro, o ayude sólo a uno de ellos [en la recolección], roba al pobre" (Peah 5, 6); o cuando el dueño de un terreno toma de la parte destinada a los menos favorecidos, como en Peah 7, 3: "El granjero también roba al pobre cuando coloca una cesta en el suelo para atrapar las uvas que caen de las matas para prevenir que sean clasificadas como 'uvas caídas', las cuales serían elegibles para que las tomaran los pobres". Por lo tanto, toda esta legislación estaría ubicada dentro de una ética que garantice la ayuda al necesitado y que revierta en la justicia social, en una mejora de la sociedad a través de sus integrantes, llevando al ideal, como consecuencia, del tikkun ha-olam o "reparación del mundo". No obstante, más allá de esto, evoca a que las buenas acciones, entre ellas la de la limosna y la caridad, serían retribuidas por efecto, 
o castigadas en el defecto de su cumplimiento; esto es, no sería una cuestión opcional sino, a tal punto, preceptiva.

El concepto del tikkun ha-olam —esto es el propósito de la corrección del mundo en el que uno de los puntos fundamentales es la paliación de las desigualdades sociales - comienza con una serie de regulaciones legales que así lo posibilitan. Sin embargo, este ideal ya se señala en el texto bíblico en solamente tres ocasiones en Qohélet (Eclesiastés 1, 15; 7, 13 y 12, 9) con el significado de reparar. En la literatura rabínica, por otra parte, aparece una treintena de veces en la Mishna y la Guemará asociada, sobre todo, a las leyes de divorcio en el tratado Gittin, por lo que este principio, originalmente, se dedicó a proteger los derechos de las mujeres en aquellos casos:

Al principio, un hombre [que había enviado a su esposa a un divorcio por mensajería] establecería un tribunal religioso en un lugar diferente [desde donde vivía la esposa] y cancelaría [la declaración de divorcio]. Rabban Gamliel el Viejo promulgó que no podrían hacerlo, debido a Tikkun Ha-Olam. Al principio, un hombre podía cambiar su nombre y el de ella, el de su ciudad o el de su ciudad. Rabban Gamliel el Viejo promulgó que uno escribiría: "El hombre, tal y tal, y cualquier otro nombre que tenga, y la mujer, tal y tal, y cualquier otro nombre que ella tenga", debido a Tikkun HaOlam. [...] Hillel instituyó el prozbul [una exención emitida por la corte de la cancelación del año sabático de un préstamo personal] debido a Tikkun Ha-Olam (Mishná Gittin 4, 2-3). (Rosenthal, 2005, p. 217)

Más tarde, se extendió al plano económico y comercial, de acuerdo con Deuteronomio $15,1-3$, en lo concerniente a la regulación de personas que necesitaban que se les prestara dinero y que eran rechazados por los fiadores conforme el año sabático se aproximaba, por lo que cualquier deuda adquirida con estos era aniquilada según la ley judía (Rosenthal, 2005, p. 218). Como consecuencia de esto, el término se movilizó a una nueva esfera: la religiosa y humanitaria (Rosenthal, 2005, p. 219), que tuvo eco en el campo de la filosofía judía medieval, en el sentido de perfeccionar el cuerpo, el alma y las virtudes mediante una literatura ética encargada de difundir 
valores morales, hasta llegar a los siglos XVI y XVII. La mística judía también se ocupó de este integrándolo en los escritos cabalísticos (Sherwin, 2014). En este sentido, además, el valor de la tsedaqá posee un significado muy importante, pues la caridad, la limosna y socorrer a un necesitado se tratan extensamente en esta literatura, divulgándose y transmitiéndose entre los miembros de las familias, pero, igualmente, en comunidades incluso alejadas entre sí de Oriente y Occidente.

Con este legado, este concepto aparece en la contemporaneidad como la acción y la justicia social, en las que estarían incluidas también la paz social, la igualdad, la responsabilidad ecológica y las no desigualdades económicas en este modo de hacer de la sociedad un conjunto mejor, a través de una reparación de todos aquellos ámbitos que comportaran desigualdades (Rosenthal, 2005, p. 239).

Es necesario apuntar que estos términos, sus imbricaciones en la sociedad y las consecuencias que se buscan bajo el amparo de su regulación, se combinan para llegar a un ideal en el que el mundo sea perfecto en el sentido de eliminar o, al menos, paliar las situaciones de injusticia, donde se incluyen las desigualdades sociales en el terreno del pobre. De esta forma, la tsedaqá es un instrumento fundamental para ello. Esta es transmitida de manera escrita y oral a lo largo de las generaciones, no solamente a través del estudio de la ley y los textos fundamentales del judaísmo, sino mediante una literatura adaptada a la ética. Sin embargo, la tsedaqá, en cuanto a parte integrante del complejo entramado para llegar a una perfección del mundo, está enraizada con la paz como veremos a continuación.

Ya en el mismo saludo tradicional hebreo está implícito el sentido de paz. Así, la palabra Shalom (paz) no solamente funciona para dar la bienvenida a alguien, sino su significado se extiende al de algo completo, terminado, restaurado, restituido. Como Gómez Pineda refiere (2016, p. 208), para el pensamiento semita-hebreo Shalom es una expresión común que implicaba la idea de pedir a Dios que guardara íntegramente (Nm. 6, 22-26) y no solo que librara de la guerra o alguna desgracia. Esto es así, porque el pensamiento semita antropológicamente entiende el ser humano unisolo, tal cual expone el autor $-\mathrm{y}$ no dual o tripartito como algunas corrientes grecolatinas_ $-\mathrm{y}$ explica: 
El ser humano es una totalidad donde si bien se puede encontrar un espíritu y un alma, estas en ninguna forma están divididas o separadas, sino que hacen parte de una totalidad; por lo tanto, el bien-estar es integral y la paz entonces es vista como totalidad, implicando una integridad y plenitud de toda la persona y, por ende, de la totalidad de la comunidad. Esto queda confirmado en la expresión shālèm que se desprende del verbo shālàm. Shālèm significa: estar completo, estar sano, es decir, la ausencia de guerra como idea de paz según Kant, en el pensamiento semita, sería un aspecto entre muchos que está en la shālôm, la cual busca el estado pleno del ser, el estar en total bienestar tanto físico, emocional y espiritual. Así que lo anterior nos da la primera consecuencia práctica ético-moral de la idea de la shālôm hebrea como paz: la paz es bienestar-integral físico [...] pero en su esencia la realidad es el aquí y ahora y, por lo tanto, para que se dé la paz esta se debe construir sobre unos mínimos que garanticen no solo la sobrevivencia humana, sino el bien-estar en general, el sentirse bien, el disfrutar. (2016, pp. 208-209)

Este es el punto en el que los instrumentos para la consecución de la paz, como la tsedaqá, se vuelven imprescindibles, ya que contribuyen a esa restitución del mundo ideal a través de los menos favorecidos:

[...] para el pensamiento semita hebreo, la justicia se entiende como todo aquello que puede llevar a la rehabilitación o restitución del estado ideal del ser humano como imagen de Dios. Aún la justicia retributiva o punitiva, buscaba en últimas rehabilitar o habilitar de nuevo al individuo para volver a ser imagen de Dios. Es decir, la justicia como ideal humano y la justicia a nivel formal como cuerpo de mandamientos, reglas y principios que deben ser administrados por los órganos de justicia y acatados por el pueblo, tienen como finalidad el bien-estar integral del ser humano, en especial de aquellos más vulnerables y en condiciones menos favorecidas. (Gómez Pineda, 2016, p. 216 que lo recoge de Spicq, 1979, p. 215)

De esta manera, la rectitud que se observa dentro de la misma tsedaqá, en el sentido de justicia, lleva a las condiciones indispensables para el cumplimiento de la paz. 
Uno de esos modos de llegar a ella será la donación de limosnas. Es allí, en las palabras del sabio erudito Hillel (110 a. e. c. -10 d. e. c.), donde las afirmaciones anteriores toman mayor relevancia: "muchas limosnas, mucha paz".

\section{LA JUSTICIA SOCIAL Y SU TRANSMISIÓN: LA LITERATURA POPULAR}

La literatura popular desempeña un papel esencial en la transmisión de conocimientos religiosos, entre los que es conveniente incluir aquellos relativos a la caridad y la limosna que se extienden a un plano ético y justo. En este sentido, los cuentos y las leyendas son una de las formas más deseables, ya que, por su extensión, su circulación oral es más factible. Es más, ciertamente las cadenas de transmisión pueden ser justificadas a través del mismo texto bíblico. En Deuteronomio 4, 9: "Solo que guárdate y ten mucho cuidado de ti para no olvidarte de las cosas que tus ojos han visto y que no se aparten de tu corazón en todos los días de tu vida; pero hazlas a tus hijos y a los hijos de tus hijos".

Este es el caso del conjunto de leyendas que veremos a continuación, publicadas originalmente en Túnez, en lengua judeoárabe, aunque, como ya apunté, su recorrido oral se remonta incluso a siglos atrás. Es muy interesante hacer alusión al contexto cultural en el que surgen, pues lo hacen bajo el amparo de las últimas consecuencias del movimiento de la Ilustración judía (siglos XviII y xIx), que surge de manera paralela a la Ilustración europea. Esto contribuyó a la modernización de las comunidades judías en Oriente y Occidente y en el que uno de los elementos centrales era la divulgación del conocimiento.

Este conocimiento se relacionaba estrechamente también con los contenidos éticos y morales. Utilizaba como protagonistas a rabinos y personajes relevantes de la tradición judía, de cuyas anécdotas o ciertos aspectos de su vida se ofrece una lección moral; o, por otra parte, a personajes anónimos que están inmersos en una situación complicada que consiguen resolver y de la que se desprende una enseñanza. Muchas de estas historias, con mayor o menos similitud, aparecen en otras tradiciones, pero también dentro del caudal de la literatura hebrea medieval, nutriéndose normalmente 
de las historias contenidas en la literatura talmúdico-midrásica o con una clara referencia a ellas (García Arévalo, 2016, p. 25).

Como referimos, las narraciones llevan una enseñanza implícita y, en muchas ocasiones, esta es precisamente la de las acciones de misericordia en lo relativo a la ayuda al más necesitado y, por ende, a la limosna y la caridad. En la Leyenda de Sodoma, por ejemplo, se hace alusión a que la gente de la ciudad había sido castigada por Dios por todos los hechos injustos que habían cometido:

En cuanto a Lot y a sus dos hijas, se habían protegido en una cueva apartada y aquí habían estado muchos días. Cuando se levantó Abraham en la mañana para ver las ciudades de Sodoma, encontró que se habían convertido en humo. Se había quemado toda la gente, los animales, los pájaros y la ciudad se había convertido en una ruina y en una sombra. Esta fue la retribución de la gente injusta que cometía hechos ilícitos y, en cuanto a aquellos que hacían el bien, el Clemente fue bueno con sus castigos en este mundo y en el otro. (García Arévalo, 2016, p. 264)

También se hace referencia a hechos ilícitos como no ser misericordioso con el extranjero que llegaba a la ciudad y no ofrecerle invitación para quedarse en su casa o no dar limosna:

Ninguno le daba al extranjero que pedía limosna nada a excepción de un franco. Cada uno escribía su nombre en su franco y en el país promulgaban una orden estatal para que ninguno le vendiera a aquel extranjero nada de comer. Y aquel extranjero, el pobre, con su dinero en la mano, daba vueltas por las calles de la ciudad y no encontraba quien le vendiera algo de comer hasta que moría aquel desgraciado de hambre. Y, después de que muriera, iba cada uno y cogía su franco con su nombre escrito en él. Después se producía entre ellos una discusión por la ropa y por las cosas que llevaba en su cota de malla, se la quitaban y la cogían. Después lo levantaban y lo enterraban desnudo debajo de cualquier árbol a las afueras de la ciudad. Y así hacían con todo aquel extranjero que se les moría. (García Arévalo, 2016, pp. 259-260) 
De la Leyenda de rabi Yehoshua ben Levi (rabino palestinense de la primera mitad del siglo III d. e. c., Neusner, 2003, p. 265-267) con el profeta Elías - tras el periplo del primero con el segundo, a quien acompaña por el mundo sin entender su modo de proceder para con aquellos con los que se encuentra - se extrae la siguiente enseñanza:

Y si Dios te enriquece con bienes y posesiones, da para la limosna que se te ordena por todo camino recto y ella es la que te librará de la muerte. Aumentará tu descendencia y alargará tus días en el bien y te bendecirá Dios, tu Altísimo, en todos tus actos, amén. (García Arévalo, 2016, p. 283)

Aquí se introduce una consideración interesante: dar limosna, o no hacerlo, es retribuido con carácter positivo o negativo, incluso puede salvar a la persona de la muerte o acarrearla. Justamente este es el propósito de la Leyenda de rabi Meir ba'al ha-Nas (rabino del siglo II d. e. c. de Palestina, Herranz Pascual, 1997, pp. 125-137) con rabi Yehuda ha-Antoti (personaje de carácter anónimo del que no hay constancia en las fuentes, ya sea porque únicamente fue conocido en el círculo más cercano de los creadores y transmisores de los relatos o porque su importancia quedó relegada a la comunidad en la que desarrolló su actividad, aunque su carácter ficticio no es descartable, García Arévalo, 2016, p. 89) en la que el hilo conductor de la historia es la caridad y la intención sincera de ayudar al necesitado y las consecuencias de no hacerlo. De hecho, esta historia se mueve en varias esferas: en primer lugar, la del hombre que no cumple las obras de misericordia (rabí Yehuda); en segundo lugar, la de aquel que sí ayuda desinteresadamente, aun poniendo en peligro su vida (rabí Meir); en tercer lugar, las consecuencias del no cumplimiento de la caridad, que son castigadas por Dios con la muerte; y, en cuarto lugar, el arrepentimiento del protagonista, que trae consigo la retribución positiva por parte de Dios a quien es consciente de sus errores:

Leyenda que sucedió en los días de rabí Meir ba’al ha-Nas, su recuerdo permanezca entre nosotros, amén, que siempre salía de la oración a las diez de la mañana. Sucedió que un día mientras rezaba la oración de la mañana, salió temprano corriendo y, después de que saliera, se quedó maravillado 
consigo mismo y dijo: “¿cuál es el significado de que haya salido de la oración temprano? Puede que Dios quiera hacer hoy un milagro a través de mí". Mientras que estaba parado pensando durante unos instantes, vio una pareja de serpientes cruzando y, una de ellas, preguntó a la segunda: “¿A dónde vas?”. Le respondió: "Dios me envió para matar a rabí Yehuda ha-Antoti, a él, a sus hijos, a sus hijas y a toda su familia". Siguió preguntándole la serpiente: "No sabes el porqué de este gran castigo?" Le contestó: "En su vida nunca dio limosna de sus bienes” y cuando escuchó rabí Meir estas palabras, dijo con todo su corazón: "iré a su casa y veré si es cierto y lo salvaré a él y a su familia de esta desgracia que se cierne sobre él”.

Después de aquello, cogió rabí Meir un pan tierno y le dijo a rabí Yehuda: “Toma este pan y dámelo diciendo 'toma este pan para ti como limosna'”. Le dijo rabí Yehuda "no te lo daré porque comiste hasta saciarte y es suficiente".

[...] dijo rabí Yehuda [refiriéndose rabí Meir]: "bendito sea tu nombre que hizo conmigo un milagro y me salvó de la muerte”. Le dio las gracias a rabí Meir y le juró que él, todo pobre que cayera en su mano, no se iría con las manos vacías. Por esto aprendemos que todos nuestros hermanos de Israel, conocedores de la misericordia, serán todo el tiempo misericordiosos con los pobres y esto está en sus oraciones, como lo que dice el versículo "la limosna te librará de la muerte', es decir, que quien te dé limosna, se salvará de la muerte y vivirá una vida llena de prosperidad y plenitud". (García Arévalo, 2016, pp. 283-285)

La Leyenda sobre la limosna es mucho más específica en cuanto a su temática, pues está dedicada íntegramente al ofrecimiento de la caridad. Junto con ello, el carácter anónimo de sus personajes, únicamente representados por los valores morales que protagonizan y que son cambiantes de acuerdo con el desarrollo de la historia, supone una universalidad de su enseñanza:

Había un hombre malvado y durante toda su vida había cometido injusticitas. Cuando le llegó la enfermedad en la estera de la muerte, su gente y los que 
estaban en la casa, le rogaron que comiera algo. Les pidió un gran caldo y, cuando se lo llevaron y quiso comérselo, entró un pobre y le pidió algo de comer. Le dijo el enfermo a su gente: "dad el caldo, dadlo a aquel pobre". Y así este enfermo, que en su vida había dado limosna, hizo esta grandeza. Y aquella semana murió el enfermo y fue enterrado. Después de unos días, el hijo, el mayor, soñó con él, deteniéndose frente a él y preguntándole: "Papá ¿cómo sigues en el mundo del que te fuiste?”. Le respondió su padre: “Te recomiendo, hijo mío, que te acostumbres a hacer donaciones de la limosna y el legado, por eso de la vida y de las predeterminaciones del mundo. Porque yo, en toda mi vida, no di limosna siendo aquel caldo lo único que le di al pobre y cuando me fui de este mundo aquella grandeza venció a todos mis pecados y regresé al Jardín del Edén”. Y así reza el dicho del pueblo que dice: "quien hace el bien, lo encontrará", y es lo bueno para todos los hombres que nunca nieguen su alma y no se inquiete el que dé limosna. (García Arévalo, 2016, p. 289)

Sin embargo, también estas historias se atribuyen a los grandes rabinos de la antigüedad, hecho que les confiere un mayor poder sobre aquellos que escuchan o leen estas leyendas, como en el caso de Rab Huna, rabino de Sura del siglo III d. e. c. (Neusner, 2003, pp. 209-211):

Rab Huna tenía 400 albercas de vino y se le avinagraron y se entristeció. Entraron a su casa los sabios y dijeron: "Piensa, ¿no cometiste ningún pecado?", se apenó por ello y les dijo: “¿Venís pensando que cometí un pecado?”. Le contestaron: "Lo pensamos y no decimos que Dios te causara esta pérdida en vano, ¡Dios nos libre!”. Les dijo Rab Huna: "Si uno de vosotros conoce de mí alguna falta que me lo diga”. Le respondieron inmóviles: "Das a tu jardinero parte de la vińa que se perdió?”. Les contestó Rab Huna: “¡Sabéis que roba más de la mitad y no necesita que yo se lo dé!”. Le contestaron que cogiera del ladrón lo que calculara que hubiera robado: "e incluso si él hubiera robado, tú tienes que dárselo". Y, en aquel momento, Rab Huna aceptó darle su derecho. Fue misericordioso el Señor con él por el vinagre, aumentando mucho su precio y lo vendió y obtuvo por él bien y bendición. (García Arévalo, 2016, pp. 295-296) 
En la Leyenda de José, el hortelano, los actos de misericordia se dividen en varias categorizaciones: primero, en la misma que practica el protagonista, José, quien es despojado de sus bienes y expulsado de la comunidad, pero que sigue dando limosna aun en la pobreza; segundo, en la figura de su mujer, que se expone a ser vendida con tal de que su marido sea retribuido por Dios a través de la limosna; y, tercero, estos hechos desinteresados y que repercuten directamente en los necesitados, incluso a costa del sufrimiento por encima de las posibilidades de ambos, son recompensados, no por el hecho de la limosna en sí misma, sino por los sacrificios que han comportado:

Leyenda que sucedió en los días de rabí Eliezer y rabí Yehoshua, que salían para celebrar una fiesta al Templo. En la noche de la Expiación, se dirigieron al patio del Templo y vieron que se les acercaba un ángel, en su mano llevaba un vestido blanco que brillaba como el sol y no tenía en él ningún ribete rodeándolo. Se dijeron: "Este vestido tiene que ser para uno de nosotros". Se acercaron al ángel y le preguntaron para quién de ellos era el vestido. Les dijo: "que vuestros vestidos son mejores que este, que este vestido es para un hombre de la ciudad de Askalon, su nombre es José, el hortelano". Fueron y acabaron su camino y cuando terminaron los días de la celebración, salieron juntos para ir [a ver] al hombre de Askalon. Cuando llegaron, escucharon hablar sobre ellos a la gente de la ciudad, salieron para recibirlos, les rogaron que se hospedaran en sus casas y ellos no quisieron, dijeron: "Queremos hospedarnos en casa de José, el hortelano". Fueron con ellos algunas personas y les mostraron la casa de José, el hortelano. Cuando llegaron, lo vieron de lejos recogiendo la verdura, lo saludaron y él les devolvió el saludo y después le dijeron: "vinimos porque queremos hospedarnos en tu casa". Les dijo: "¿dejáis a toda la gente rica y venís a mi casa? Dios sabe que no tengo en mi casa sino dos panes". Le dijeron: "Lo que tengas nos es suficiente y no se te cogerá otra cosa". Se pusieron ante él, comieron, bebieron e hicieron la bendición de la comida, tras esto le dijeron: "Viste que dejamos a toda la ciudad y vinimos a hospedarnos en tu casa. Te rogamos que nos informes sobre tus hechos y tu vida".

Les dijo: "Mis señores, estáis viendo mi debilidad y mi pobreza y no tengo ningún oficio sino servir a este huerto que estáis viendo ante vosotros". Dijeron: "incluso si es así, queremos, por favor, que nos hagas saber sobre este servicio 
o qué te ha pasado". Les dijo: "Mis señores, si queréis que os haga saber qué me ha pasado, he aquí que os informaré de todo. Que sepáis que papá era de los más grandes de la ciudad y de los ricos y cuando murió, perdí todas las pertenencias que tenía. Cuando me vio la gente de la ciudad, me expulsaron y me odiaron. Salí y vine a este lugar y construí en él una casa, planté este huerto y planté en él verduras. Así es que lo que consigo del huerto, lo vendo y doy la mitad a la limosna para los pobres y la otra mitad de lo nos haga falta a mi familia y a mí. Así ha sido esta andadura hasta este momento sin ninguna desviación”. Le dijeron: "Que sepas que Dios aumentó mucho tu retribución porque Él nos mostró en mano de un ángel un vestido blanco muy brillante como el ojo del sol y cuando le preguntamos para quién es este vestido, nos dijo que este vestido es para ti, José. Y vinimos para inclinarnos hacia ti y alegrarte. Pero te decimos que el vestido aún está incompleto en el ribete que lo bordea y es por esto que quisimos venir ante ti, para hacerte saber que Dios será bueno contigo si aumentas estos actos buenos tuyos”. Cuando escuchó José, el hortelano, estas palabras, se alegró, los bendijo y les dio las gracias y lo dejaron en paz y se fueron. Cuando su mujer escuchó estas palabras, le dijo: “¡Viste que te lo dijeron los sabios! Que tu vestido no está terminado por el ribete, y ahora haz hasta donde alcancen tus fuerzas para acabar tu vestido y no lo dejes sin acabar". Le dijo a ella: "Sí, tus palabras son las palabras de una buena mujer, pero en aquel fundamento se ve y se reconoce mi pobreza y no tengo fuerzas para hacer más de lo que ya hago". Le dijo: "Escúchame, mi señor, y coge mi discurso para que te considere bueno Dios. ¡Ahora levanta, hazme salir al mercado y véndeme! Da el dinero de la limosna a los pobres y es posible que así acabe el vestido". Le dijo: "Tengo miedo de que el comprador sea un hombre malo y te llegue a hacer algo malo iy ese momento corrompa todo el vestido!". [Le contestó] "Yo te juro por los cielos que estas palabras no sucederán nunca".

Escuchó su marido su discurso y salió, la vendió en el mercado y dio su valor como limosna para los pobres, pero su señor, que la había comprado, cuando vio que era bella en aspecto y todas las buenas cualidades, quiso forzarla y no pudo. Le dijo: “iMi señor, no es posible estar contigo ni aceptar ningún mandato!". Se enfadó su señor con ella duramente y, cuanto más se enfadaba con ella, más ardía el fuego del enfado. Se levantó y se la dio al pastor de ovejas 
y le ordenó que la forzara y la solicitara sexualmente, la castigara y la golpeara con la vara. La cogió el pastor y la sedujo día tras día y cuando encontraba en ella indiferencia, la golpeaba con el palo, la marcaba y le amargaba la vida con duros servicios. Con todo eso no podía y ella se dedicó al llanto y esperaba la misericordia del cielo. Pasaron muchos días y seguían castigándola entonces su marido, un día, se coló con una espada escondida, y ella estaba siendo castigada, atada a un saco, toda ella llena de golpes y moretones. Se acercó a ella y le dijo: "¿No quieres, mi seńora, que te compre para mí para que seas mi mujer y termine tu tormento?". Le dijo a él: "Mi señor, no digas eso, porque yo soy la mujer de un hombre". La sedujo con palabras y le dio bienes y bondades. Ella no escuchó sus palabras y se abasteció de virtud y de su tormento, pues continuaba inflexible con aquellas palabras y lo afeaban. Cuando escuchó el hombre todas sus palabras, supo que ella no se oponía a su deber y tampoco rompía su pacto. Se levantó el velo de su cara y descubrió quién era pues no sabía que era su marido. Cayeron abrazados el uno al otro en un beso, y lloraron mucho y les dieron la vuelta los corazones. Salieron sus oraciones al cielo y escuchó dios sus voces. Escucharon un sonido del cielo que bajaba y decía: "Alégrate, José, el hortelano, que tu vestido acabaste y el vestido de tu mujer es mejor que el tuyo. Ve al lugar fulano y encontrarás en él un gran bien que es el tesoro de tus padres". Fue y encontró un tesoro de plata, oro y piedras preciosas, esmeraldas y diamante, muchas cosas sin número. En aquel momento, deshizo el pacto su mujer y volvió a comprarla con el dinero y dio la limosna y bienes a los pobres mucho tiempo. Vivió José, el hortelano, él y su mujer una buena vida bendecidos por Dios en lo bueno y los bienes hasta sus últimos días y momentos. (García Arévalo, 2016, pp. 252-254)

\section{Conclusiones}

El propio texto bíblico y el corpus talmúdico ya poseen instrumentos para proveer a los fieles de regulaciones específicas que supongan la ayuda a los necesitados. Todas estas regulaciones, pese al desarrollo histórico y conceptual, sí se mueven hacia el plano ético y moral, en cuanto al deber de su cumplimiento que, por otra parte, será retribuido positivamente por tratarse de actos de misericordia. La tsedaqá, en 
cuanto a su significación como limosna y, al mismo tiempo, en el sentido de rectitud, abarca el plano general y social de la mejora del mundo: su reparación, recogida en la expresión de tikkun ha-olam. Este perfeccionamiento de la sociedad en el que no hay desigualdades o, al menos, se tratan de paliar con las acciones de sus integrantes, lleva por lo tanto al reconocimiento y logro de una justicia social mediante la ética, también social. Todas ellas conformarían un ideal de paz completo en que la limosna contribuiría a su consecución total. En este sentido y pese a que ya se encuentra en los textos normativos del judaísmo, la literatura popular ha servido como un catalizador de valores morales. De este modo, su transmisión intergeneracional ha posibilitado la difusión de enseñanzas, entre ellas, la de que dar limosna es uno de los preceptos básicos.

\section{REFERENCIAS}

Alba Cecilia, A. (2004). Derecho judío. Ilu. Revista de ciencias de las religiones, (11), 11-24.

Brooks, R. (1983). Support for the Poor in the Mishnaic Law of Agriculture: Tractate Peah. Chico, CA: Scholars Press.

Brooks, R. (1990). Peah: The Talmud of the Land of Israel: A Preliminary Translation and Explanation (vol. 2). Chicago: The University of Chicago Press.

Cantera, F. e Iglesias, M. (2000). Sagrada Biblia. Versión crítica sobre los textos hebreo, arameo y griego. Madrid: Biblioteca de Autores Cristianos.

Fraijó, M. (1985). Jesús y los marginados. Utopia y esperanza cristiana. Madrid: Ediciones Cristiandad.

García Arévalo, T. M. (2016). La tradición lingüistica y literaria judeo-árabe de la Edad Media a la Edad Moderna a través de la colección Ma’aseh Sadiqim. Madrid: Consejo Superior de Investigaciones Científicas. 
Gómez Pineda, L. A. (2016). Consecuencias prácticas de la shālôm y su relación con la justicia hebrea. Franciscanum, 165(43), 203-222.

Gurfinkiel, A. G. (2017). Pensamiento económico en la tradición judía, con especial referencia a Moisés ben Maimónides: la perspectiva austriaca. Procesos de Mercado: Revista Europea de Economía Polític, 14(1), 213-255.

Herranz Pascual, C. (1997). Los sabios del Talmud. Barcelona: Riopiedras.

Idareta-Goldaracena, F. (2016). La tzedaká en la ética de E. Lévinas y A. Salomon: hacia una ética de mínimos para el trabajo social. Irahila, (62), 127-139.

Jeremías, J. (1997). Jerusalén en tiempos de Jesús. Madrid: Ediciones Cristiandad.

Kellner, M. (1995). La ética judía. En P. Singer (ed.), Compendio de ética. Madrid: Alianza.

Martínez, A. E. (2009). “Una esquina de tu corazón” (Peah): la Mishná y su compasión por los necesitados. Revista Latinoamericana de Teología, 26(76), 71-88.

Neusner, J. (2003). Dictionary of Ancient Rabbis. Peabody, Mass.: Hendrickson.

Rosenthal, G. S. (2005). Tikkum ha-olam: The Metamorphosis of a Concept. The Journal of Religion, 85(2), 214-240.

Sherwin, B. (2014). Tikkun Olam: A Case of Semantic Displacement. Jewish Political Studies Review, 25(3-4). Dor: https://doi.org/10.5569/1134-7147.62.09

Spicq, C. (1979). Dios y el hombre en el Nuevo Testamento. Salamanca: Secretariado Trinitario. 